\title{
Using BIM Technology to Optimize the Traditional Interior Design Work Mode
}

\author{
Ning Ke ZHU \\ Beijing University of Civil Engineering and Architecture, Beijing, 100044, China
}

\begin{abstract}
BIM technology and application in the field of architecture design has produced results, but BIM technology and application in the field of interior design is still immaturity because of construction and decoration engineering separation. The article analyzes the problems that BIM technology lead to the interior design work mode optimization, from the 3D visualization work environment, real-time collaborative design mode, physical analysis design mode, information integration design mode state the application in interior design.
\end{abstract}

\section{Introduction}

The Building Information Modeling technique first appeared in the United States. The concept of BIM undergo nearly 30 years. in 1975, Dr Charlie Eastman , Carnegie Mellon University initiated the "Building the Description System" (architecture Description System) working prototype, in 1984, the Hungarian Graphisoft company researched and developed architectural design software named AtchiCAD, in 1986, Robert Ash in GMW company proposed "Building Modeling" conception, the definition of Building Information Model has been updated and improved. In 2002, With the aid of continuous application of computer aided design in the construction industry and the continuous exploration in architecture engineer of the software development company, Autodesk company puts forward the concept of BIM (Building Information Modeling).

BIM technology is based on 3D digital technology, the engineering data model integrate of all kinds of information related to construction engineering project, it provided information for the design and construction with mutual coordination, internally consistent , operation. People can use BIM technology at architecture design, structure design, MEP design, construction engineer and operations management and associate them, it make a designer to focus on the design better, free designer from tedious drawing works, it help budget company work more accurate, it help construction organization work more precise and greatly improve the project progress, it help the operation management people manage and maintain the whole life cycle of construction more convenient and accurate.

In the design stage, The application of BIM technology is aimed at architectural design mainly. Several major design software, such as Autodesk Revit, Bentley, ArchiCAD, etc, have a lot of information building block libraries which is easy to adjust architecture building information modelling by means of parametric design model, and they have effectively integrated many block libraries, such as structure, water supply and drainage, electrical, HVAC and other profession, it is convenient to carry out various profession collaborative design.

In 2003, SOM applied BIM technology to the building design of the world trade center in New York City, which had a great success. Countries such as the UK, Singapore and South Korea have also applied the technology to the design and construction of buildings in large Numbers. Countries have also compiled and published BIM technical standards. In recent years, many large design units in our country have also used BIM technology in architectural design, such as table 1, and have written relevant standards.

Table 1. projects analysis using BIM technology

\begin{tabular}{|c|c|c|}
\hline Project & Description & Design Company \\
\hline Shanghai Tower & $\begin{array}{c}\text { Super high architecture design, curved } \\
\text { surfe design, various profession } \\
\text { coordination }\end{array}$ & $\begin{array}{c}\text { Gensler (USA), } \\
\text { Tongji Architecture Design } \\
\text { (Group) Co.,Ltd }\end{array}$ \\
\hline Tianjin 117 Building & $\begin{array}{c}\text { The structure of the building is 596.5 } \\
\text { meters high, realizing the integration of } \\
\text { professional model information and } \\
\text { business information, saving cost, }\end{array}$ & $\begin{array}{c}\text { The P\&T Group, } \\
\text { ARUP, }\end{array}$ \\
& $\begin{array}{c}\text { Shanghai Xian Dai Architecture } \\
\text { Design (Group) Co., Ltd }\end{array}$ \\
\hline
\end{tabular}

* Corresponding author:zhuningke@ $@$ bucea.edu.cn 


\begin{tabular}{|c|c|c|}
\hline & $\begin{array}{l}\text { improving management and standard } \\
\text { construction. }\end{array}$ & \\
\hline Zhuhai Grand Theater & $\begin{array}{l}\text { BIM technology is widely used in the } \\
\text { design of thin-wall curved surface and } \\
\text { theater interior design }\end{array}$ & China Reconstruct Design \\
\hline
\end{tabular}

Traditional Interior Design Mode

Interior design is the continuation and deepening of architecture design, which is the re-creation of interior space and environmental design. Interior design aims for the people who live in or use the space. According to the natural functional quality of the building, environment and the corresponding standards, using the material technical means and building design principle, create reasonable function, comfortable indoor environment and satisfy people's material and spiritual need. This space environment has both the use value to satisfy functional requirements and reflects the spiritual factors such as historical context, architectural style and environmental atmosphere.

\section{Question}

BIM technology has been used more and more in architecture design stage, but the study of using BIM technology in interior design has seldom been seen although the interior design is a important part of architecture design. The domestic BIM technology project also seldom has the case of combining construction engineering and decoration engineering completely. The reasons are as follows.

(1) Construction engineering and decoration engineering are separated. Usually the developer is responsible for the construction work, the work contents generally include the building main body and the exterior decoration, the internal decoration is usually very simple and isn't a detail project. As the user of the building is often uncertain when construction is completed, it is impossible to determine the internal function of the building and its decorative contents.

(2) While in construction projects, the BIM technology has been applied from time to tome, but in the next phase of the project, both the project owner and designer are not very interest in using BIM technology in indoor decoration and haven't strict requirements on that. Interior design units usually use traditional design patterns which are more comfortable and familiar. It also eliminates the manpower and time to learn and promote BIM technology.

(3) Interior design also involves multiple professional coordination problems, decoration, water supply and drainage, electrical, HVAC and even construction, etc. In the design and construction phrase, decoration design, construction engineering, electrical and other professions cross-work, the branch itemized project is more, the process is complex, it often lead to the three-side project because of catching time.

\section{Optimization of interior design work mode brought by BIM technology}

\subsection{D visualization working environment}

Visualization is a necessary result of interior design work mode, converting interior design into visual graphics can facilitate design project better and also conduce to better communication between people. In the design process, sketch, three views, and 3D model are all commonly used visualizations, each with its characteristics, and table 2 .

Table 2. visualizations of sketch, three views, 3D model

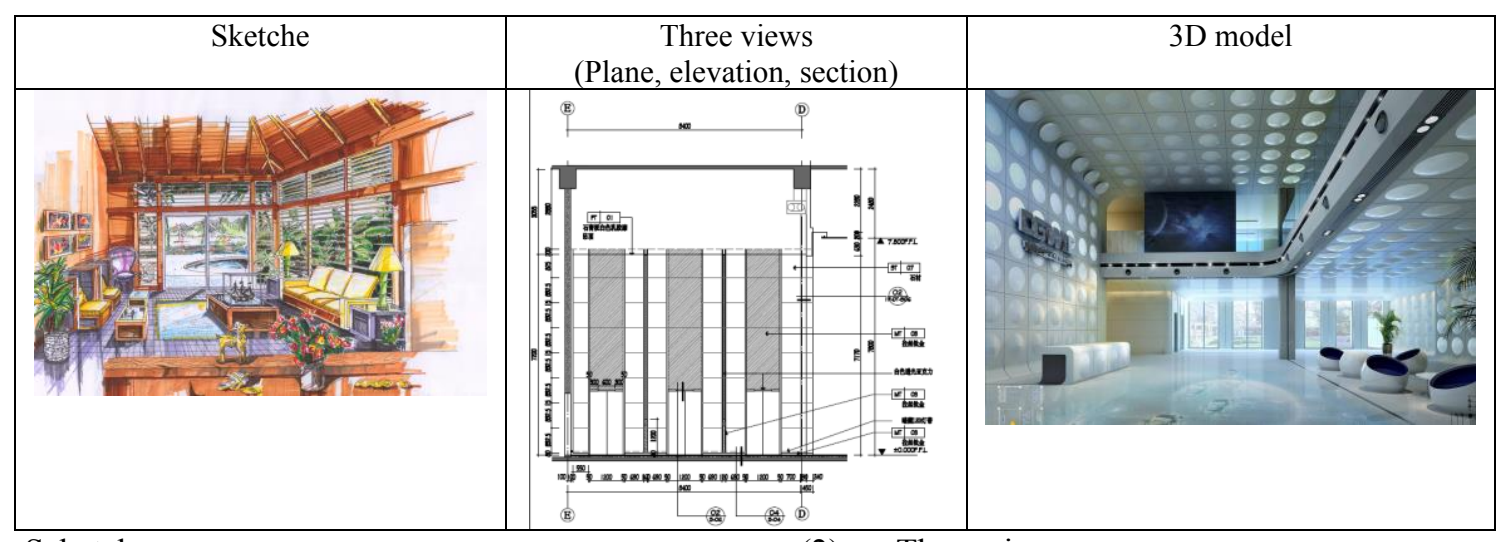

(1) Schetch

Advantages: the fastest and most intuitive way to record designers' inspiration, strong and expressive.

Disadvantages: it is difficult to be very accurate, the perspective is more random, no dimension mark, no accurate data, it is difficult to achieve the lighting, material and other effects. It is hard to achieve what you see is what you get.
(2) Three views

The three views is the most widely used visual design model, which has been used since ancient times. Three views separate a three dimensional space into different angles of view to express such as plane, elevation, section, the viewers use comprehensive analysis ability of the brain to combine different drawings and get a full recognition about the space . The advantage of the three 
views is to display the spatial shape on the two-dimensional plane, which is easy to draw and label the dimensions, and the dimensions are accurate, it also can annotate materials and other relevant information. The disadvantage is that both the drawing staff and viewers usually need professional training. The drawing person need to divide the three dimensional space in his mind into three views to draw separately, so the plane, elevation and sections will not matched often. It is necessary for viewers to combine the three kinds of drawings into a three-dimensional space to understand, it has some difficulty on spatial imagination. Due to the increasingly complex space in modern engineering, it is also inevitable to make mistakes whether in the process of segregation or the process of integration,.

\section{(3) 3D Model}

The 3D model can be divided into solid 3D model and the virtual 3D model of computer simulation. Solid 3D model is usually made in a reduced scale, so that the observer can have a bird's eye view, and the effect is real and intuitive. In interior design process, solid 3D models are used less because the its scale is small, the observer can't look at inside and also can't experience indoor space feeling and effect.

With the development of computer technology, virtual 3D models are increasingly applied to interior design. 3ds Max, Sketchup, Autodesk Revit and other softwares can accurately model and render, so that the designer and the viewer can visually observe the interior space, materials and details from different angles.

BIM technology is more closely designed with "real" $3 \mathrm{D}$ visualization mode. The designer directly constructs the model in 3D space, and the model has real space information, construction information, material information and cost information. Designers not only can observe the indoor space from any Angle, but also can simulate sunlight and material effects at any time, realizing real-time design, real-time modification and real-time vision.

\subsection{Real-time Collaborative Design Mode}

BIM model is an open, Shared, update design work platform that provides a platform for real-time collaborative design. According to the characteristics of the interior design, interior design collaborative process which based on building information model can be divided into: internal work in interior design, external work in different profession, interior design and related products. All three collaborative work is based on the web, but they are in different ways. Internal collaborative work mainly based on working set, external collaborative work mainly based on links, interior design and related product design is accomplished by information model data library.

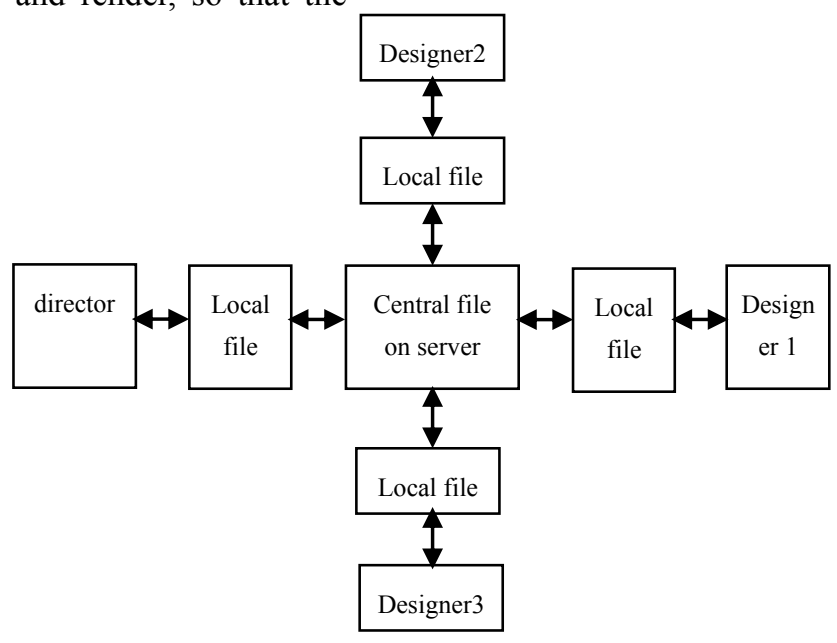

Figure 1. Building Information Model Set

The work set can divide the permissions between team members and save the information model to local computers and servers to realize the relative independent work of team members on the same model. As shown in figure 1, both director and ordinary designers, their design information are passed through the central file which ensures that all people are working on the same working model, and "graph combining" between each member is highly automated.

The link can be used to combine interior design model with other equipment models (water supply and drainage, electrical, HVAC) into the same information model. Various professional designers can be easily read other professional design file and check the collision conflict problems, in this stage, interior designer is usually responsible for the whole coordination, form the final results.

The information resource library provided by the indoor building information model connects the up industry and down industry, including interior designers, product designers, manufacturers and so on. The information library can include appearance, material, price, service life, etc.

\subsection{Physical Analysis Design Mode}

In past, physical analyses of Interior space environmental in the interior design are often ignored, designers usually just do it according to the experiences. for example, about intensity of illumination of indoor lighting, designer usually set indoor lights and supply power usually according to the illuminance standard in different 
space which caused a lot of energy waste, and didn't meet the need of highlighting key space and key lighting. In recent years, with the gradual deterioration of the ecological environment, indoor decoration has caused a quality of kinds of diseases and more and more people has been caring about it. Aiming at this kind of phenomenon, the new revision of 《The Green Building Evaluation Standard 》 (GB/T 50378-2014) was implemented on January 1, 2015, in 《The Green Building Evaluation Standard》, indoor environment quality has a separate section, it give specific requirements on acoustic environment, light environment, thermal environment and air quality in interior space. Obviously, it is difficult to achieve these requirements by rough experiences, it requires the application of a professional computer-aided design tool. BIM technology is an effective means to realize simulation and verification which provides a platform to cooperate with related professional software.

In light environment simulation, the domestic main lighting calculation software are DIALux, AGi32, etc, the BIM model can be imported to lighting design software, after illumination calculation and setting lights, it can quickly get illumination calculation results of working face and show it in the graphic. As figure 2.

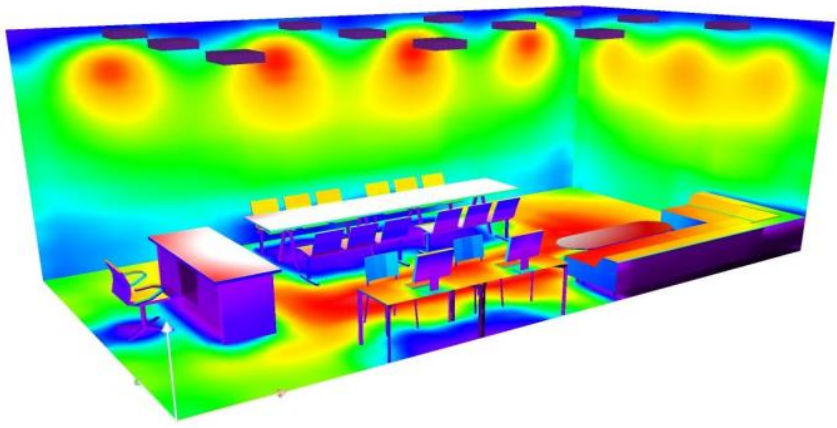

Figuire 2. Illumination calculation in meeting room

In acoustic environment simulation, acoustic calculation (mainly reverberation time) mainly depends on the type of decoration materials, sound absorption coefficient and area, which requires a large amount of data calculation. BIM model can be convenient to count data of decorate material and output forms. Base on this form, by writing acoustic formula in Excel spreadsheet, the calculation and adjustment of reverberation time in interior space becomes extremely fast.

In thermal environment simulation, the BIM model can accurately simulate the location of the building and simulate the irradiation of natural light. The model can also be imported into the relevant software to simulate air flow and calculate it, which can achieve the comfort of the space environment and reduce the energy consumption.

Indoor air quality optimization refers to natural ventilation and controlling of harmful substances in decoration materials, especially formaldehyde, benzene, ammonia, radon, etc. While establishing BIM model, it builds the decoration material data library which records the relevant physical data of the material. using the statistical function, BIM software can calculate the content of the harmful substances such as VOC in each room. Using BIM technology, the air quality control can be advanced to the design construction stage, instead of putting activated carbon or green planting into space when the decoration project has been finished.

\subsection{Information integration design model}

The building information model, by using BIM technology, is definitely not a simple geometric solid, but is a set of components with data attributes. On the platform of building information model, all kinds of information rely on each other. Interior designers constantly optimize their design project by this model, and pass the information model to the entire building life cycle, which can realize to reuse the information model in different professions and different stage, and constantly improve it.

In the BIM model, the model is not a simple geometry solid, but many components with attributes and constraints. As shown in figure 3 , the door has its own attribute definition, elevation, etc. The width, height and position of the gate could be adjusted at any time in the design. The wall attached to it will be adjusted automatically, as well as the plan and other views. In the same way, the wall in the BIM model is divided into structure, substrate and surface layer, and the thickness of each layer can be defined. The building information model established by this method is not only an information model for interior designers, but it can be transmitted and Shared among different professions. By putting the model into the building physical environment analysis software, the indoor physical environment of the space can be analyzed. The designer can optimize the project further base on the acoustic, light, heat analysis results. The collision error can be checked through the comprehensive model of water, heat, electrical engineering. This model is used for view switching, and to generate 2D drawings, 3D models, animation, etc.

In the whole life cycle of Building information model, different participants, such as the owner, design units, government departments, supervision unit and construction unit, material suppliers, operations management, etc. will work on it. Various departments communicate information through the same building information model which can greatly save energy, reduce waste and improve efficiency.

\section{Conclusion}


If BIM technology has been used effectively in architectural design, the design institute and design company that applied BIM technology for interior design is still in the beginning. The visual design model of BIM technology is more comprehensive, more straight and more efficient, which provides new design thinking and design methods for interior designers. As an important part in the whole life cycle, interior design can't avoid BIM reform. Fortunately, BIM technology is becoming more and more humanized, and the technical threshold is getting lower and lower. But at the same time, the design institute and design company should adjust the business model and train a group of designers who master BIM technology and promote BIM technology in interior design in the whole industry chain.

\section{References}

1. Luo Heping. The Application of Bim Technology In Interior Design Field [J]. Shanxi Architecture, 2016 (4): $257-258$.

2. Luo Lan, Zhong Fan. Application Research of Bim Technology Based On Sketchup [J]. Journal of Information Technology in Civil Engineering and
Architecture, 2015 (4): 37-42.

3. Luo Lan, Wang Fang. A Project Decoration Project Is Based On Revit BIM Technology Application Research [J]. Journal of Information Technology in Civil Engineering and Architecture, 2014 (8): 55-61.

4. Xiong Peng. Interior Design Based On Building Information Model (BIM) [J].Popular Science, 2016 (10): 150-151.

5. Liu Liejun. Interior Design In Information Age Building Information Model And Its Application In Interior Design [J]. Art \& Design. 2010. 2:125-126.

6. Jia Shuang, Shen Xiaowei, Zhang Baogang. Application Analysis Of Green Building Design Based On BIM Technology [J]. Shanxi Architecture, 2016 (4): 209-210.

7. Asojo A O. An instructional design for Building Informa-tion Modeling (BIM) and Revit in interior design curriculum[J].Art, Design \& Communication in Higher Education.2013, 11(2) :p143-154. 